\title{
An exploration of the 'African (Union Commission's) perspective' of quality and quality assurance in higher education: Latent voices in the African Quality Rating Mechanism (AQRM)
}

\author{
Lazarus Nabaho and Wilberforce Turyasingura* \\ doi: http://dx.doi.org/10.18543/tjhe-6(2)-2019pp73-95
}

Received: 28-12-2018

Accepted: 19-04-2019

\begin{abstract}
Quality assurance of African higher education is at the top of the region's development agenda. Prompted by the imperative to enhance the quality of higher education, the Africa Union Commission is implementing the African Quality Rating Mechanism (AQRM). The AQRM is a continental tool that affords higher education institutions an opportunity to conduct self-assessment and compare their performance against similar institutions based on a set of common criteria. The mechanism is envisaged to engender institutional cultures of quality and enhance the quality of African higher education. However, a dearth of knowledge exists about the latent notions of quality in higher education that the AQRM aims to assure and the implicit institutional-level quality assurance practices in the AQRM. Therefore, this interpretivist article, based on a review of the AQRM survey questionnaire, answered the following research question: What notions of quality in higher education and the institutional-level quality assurance practices are inherent in the quality standards of the AQRM survey questionnaire? The findings revealed that quality as fitness for purpose and exceptional are the notions of quality in higher education in the AQRM. Nevertheless, fitness for purpose is the dominant notion of quality and this symbolises an imperative to re-direct higher education to serve social and economic ends. Distinguished (excellent) teacher awards, applied research excellence awards, staff professional development, tracer studies, external examination, and the involvement of key external stakeholders in programme development are the latent institutionallevel quality assurance practices in the AQRM. These quality assurance practices are in sync with the notions of quality and aim at bridging the gap between the academy
\end{abstract}

* Lazarus Nabaho (Inabaho@umi.ac.ug) is a Senior Lecturer at Uganda Management Institute. Wilberforce Turyasingura (wturyasingura@umi.ac.ug) is the Dean of the School of Business and Management at Uganda Management Institute.

More information about the authors is available at the end of this article. 
and the labour market. Methodologically, the AQRM survey questionnaire is devoid of benchmarks to inform the rating, and quality assurance practices such as student evaluation of teaching, peer observation of teaching and moderation of examination items are unnoticeable in the survey questionnaire.

Keywords: Quality; quality assurance; perspectives; Africa; African Union.

\section{Introduction}

Higher education in Africa has - after over two decades of neglect triggered by the World Bank's neoliberal prescriptions of the 1980s assumed unparalleled importance in history. ${ }^{1}$ It is scarcely surprising that 'revitalising of higher education' are watchwords in the African Union Commission's education strategic frameworks: the Second Decade of Education Africa Action Plan (2006-2015) ${ }^{2}$ and the Continental Education Strategy for Africa (CESA) (2016-2025). ${ }^{3}$ In the current development discourse, higher education is stressed as a key driver of socio-economic development ${ }^{4,5}$ and a tool at Africa's disposal to achieve the African Union's vision of a peaceful, integrated and prosperous Africa. ${ }^{6}$ Specifically, higher education is regarded as an instrument with incomparable potential to facilitate the region to leapfrog the current development challenges as well as to provide intellectual muscle to tackle future development challenges. This new faith in the potential of higher education stems from the conviction that it is through post-secondary education that Africa's human resources will be nurtured and developed, Africa-led solutions for addressing African challenges will be developed, and Africa will play a role in the global

${ }^{1}$ Karola Hahn and Damtew Teferra, "Tuning as instrument of systematic higher education reform and quality enhancement: The African experience," Tuning Journal for Higher Education 1, no. 1(2013): 142-43, http://dx.doi.org/10.18543/tjhe-1(1)-2013pp127-163.

2 African Union, Second Decade of Education for Africa (2006-2015) Plan (Addis Ababa: African Union, 2006).

${ }^{3}$ African Union, Continental Education Strategy for Africa: 2016-2025 (Addis Ababa: African Union, 2016).

${ }^{4}$ World Bank, Constructing knowledge societies: New challenges for tertiary education (Washington, DC: World Bank, 2002).

${ }^{5}$ David E. Bloom, David Canning, Kevin Chan, and Dara Lee Luca, "Higher education and economic growth in Africa," International Journal of African Higher Education 1, no. 1 (2014): 23-57, https://doi.org/10.6017/ijahe.v1i1.5643.

${ }^{6}$ African Union Commission, Agenda 2063: The Africa we want (Addis Ababa, African Union, September 2015). 
knowledge economy and claim her rightful place. ${ }^{7}$ This appreciation of the indispensable role of higher education in development rekindles the post1960 idea of an African development university, a notion that was echoed by the former UN Secretary-General, Kofi Annan, in his address upon receipt of an honorary degree from the University of Ghana:

I believe that the university must become a primary tool for Africa's development in the new century. Universities can help develop African expertise; they can enhance the analysis of African problems; strengthen domestic institutions; serve as a model environment for the practice of good governance, conflict resolution and respect for human rights; and enable Africa academics to play an active part in the global community of scholars. ${ }^{8}$

Quality assurance is integral to the drive to revitalise higher education and research in Africa and has, since the mid-2000s, become part of the contemporary agenda of African governments, the Regional Economic Communities (RECs) and the African Union. ${ }^{9}$ The mutation of quality assurance from a peripheral to a topical issue in the higher education policy - at national, sub-regional and regional (or continental) levels - has been fuelled by the awakening to the notion that "today, more than ever before in human history, the wealth - or poverty - of nations depends on the quality of higher education" 10 and recent empirical studies that demonstrate a correlation between a country's productivity and the quality of its higher education. ${ }^{11}$ Consequently, there has been an unprecedented burgeoning of quality assurance agencies, with 21 African countries having established quality assurance agencies by 2012 while several others were in advanced stages of establishing them. ${ }^{12}$ At the African Union level, quality assurance is a

7 Olusola Oyewole, "The African quality rating mechanisms: The process, prospects and risks" (paper presented at the Fourth International Conference on Quality Assurance in Higher Education in Africa and Capacity Building (Training)Workshop, Bamako, October 5-10, 2010), 1-2.

8 "Information Technology should be used to tap knowledge from greatest Universities to bring learning to all, Kofi Annan says," United Nations Information Service, published August 2, 2000, https://www.un.org/press/en/2000/20000802.sgsm7502.doc.html.

${ }^{9}$ Lazarus Nabaho, Jessica Aguti, and Joseph Oonyu, "Making sense of an elusive concept: Academics' perspectives of quality in higher education," Higher Learning Research Communications 7, no. 2 (2017): 27, https://doi.org/10.18870/hlrc.v7i2.383.

${ }^{10}$ Gillis Malcolm (1999) cited in World Bank, Constructing knowledge societies: New challenges for tertiary education (Washington, DC: World Bank, 2002), 15.

${ }_{11}$ Bloom David et al., "Higher education and economic growth in Africa."

12 Juma Shabani, Peter Okebukola, and Olusola Oyewole, "Quality assurance in Africa: Towards a continental higher education and research space," International Journal of African 
strategic objective in the CESA and the continental political body is currently implementing the African Higher Education Harmonisation Strategy, which comprises a range of key instruments several of which are yet to be developed. ${ }^{13}$

The African Higher Education Harmonisation Strategy is an overarching policy framework that was adopted by the Conference of African Ministers of Education in 2007 and envisions an African Higher Education and Research Space (AHERS) along the lines of the European Higher Education Area (EHEA) - an outcome of the Bologna Process, which started in Europe in $1999 .{ }^{14}$ The strategy arguably symbolises a political commitment at the African Union level to improve the quality of higher education on the continent. The African Higher Education Harmonisation Strategy was a response to the vision of an integrated Africa, and endeavoured to resuscitate the Arusha Convention (1981), which envisaged mutual recognition of qualifications in African states, as a major tool for the integration process. The desire to synchronise the diverse higher education systems which have roots in multiple national and colonial legacies across the region motivated the development of the strategy. The multiple higher education systems albeit with identical aims - undermine mutual recognition of qualifications across the countries and further militate against African integration and the unfettered mobility of students, graduates and academics across the continent. Therefore, harmonisation of African higher education is anticipated to establish compatible structures and systems to facilitate academic mobility and foster the comparability of qualifications. We need to add a caveat: harmonisation of higher education is not analogous to homogenisation or creation of identical national higher education spaces. Harmonisation of higher education is conscious of the national-level cultural and contextual peculiarities. Harmonisation of higher education in the context of Africa may be construed as the "narrowing of variance in structural factors, processes, qualification frameworks, quality standards, degree cycles, and credits." 15

Higher Education 1, no. 1 (2014): 139-171, https://doi.org/10.6017/ijahe.v1i1.5646.

13 Juma Shabani, "Quality regimes in Africa: The reality and the aspirations," Chronicles of Higher Education 4 (May 2013), http://www.inhea.org/wp-content/uploads/2016/02/ Quality-Regimes-in-Africa-For-posting.pdf.

${ }^{14}$ Lazarus Nabaho, "Developing generic competences in life sciences: The untold story of the Makerere University College of Health Sciences in Uganda," Tuning Journal for Higher Education 4, no. 2 (2017): 391, http://dx.doi.org/10.18543/tjhe-4(2)-2017pp389-406.

${ }^{15}$ Emnet Woldegiyorgis, "Conceptualizing harmonization of higher education systems: The application of regional integration theories on higher education studies," Higher Education Studies 3, no. 2 ( 2013), https://doi.org/10.5539/hes.v3n2p12. 
The African Harmonisation Strategy comprises a number of key instruments: the African Standards and Guidelines for Quality Assurance (ASG-QA), the African Quality Rating Mechanism (AQRM), the PanAfrican Quality Assurance and Accreditation Agency, the African Continental Qualifications Framework, and the African Credit Accumulation and Transfer System. These instruments constitute the Pan-African Quality Assurance and Accreditation Framework (PAQAF), which was endorsed by the African Union Commission in 2016. The aim of the framework is to facilitate the creation of a harmonised quality assurance regime and procedures and is essential to the reinforcement of a harmonised system in Africa. ${ }^{16}$ The development of a harmonised quality assurance and accreditation system at institutional, national, sub-regional and continental levels is being supported by the African Higher Education Quality Assurance and Accreditation (HAQAA) Initiative - an initiative funded by the European Union Commission in partnership with the African Union Commission. The first phase of the HAQAA Initiative (2015-2018) was implemented on behalf of the African Union Commission and the European Union Commission by a consortium of five organisations: the University of Barcelona as the coordinator, the Association of African Universities (AAU), the German Academic Exchange Service (DAAD), the European University Association (EUA) and the European Association for Quality Assurance in Higher Education (ENQA). The African Standards and Guidelines for Quality Assurance (ASG-QA) of higher education were developed and published in December 2018 under the first phase of the HAQAA Initiative.

The Tuning Africa Project is a European Union Commission-funded initiative that was launched in 2011 and is intended to promote the implementation of the Harmonisation Strategy. ${ }^{17}$ Tuning of higher education is "a collaborative process that involves major higher education stakeholders from specific subject areas in curriculum development to enhance student competences." 18 The tuning approach concentrates on generic and subjectspecific competences, student workload (credits), teaching and learning approaches, and assessment strategies. The Tuning Africa Project, whose second phase ended in 2018, focused on eight subject areas - Agriculture, Applied Geology, Civil Engineering, Economics, Higher Education Management, Mechanical Engineering, Medicine and Teacher Education -

16 Peter Okebukola, "Emerging regional developments and forecast for quality in higher education in Africa" (Paper presented at the 2014 CHEA International Quality GROUP Annual Conference, Washington DC, USA, January 29-30).

17 Shabani, "Quality regimes in Africa."

18 Shabani, "Quality assurance in Africa." 
and involved 42 countries, 109 universities and 124 representatives, regional bodies in charge of higher education and students. A remarkable outcome of the Tuning Africa Project has been the identification of 18 generic competencies for higher education in Africa. Hahn and Teferra ${ }^{19}$ credited the Tuning Africa Project with developing “.... an improved understanding of graduates' competences that are relevant to a variety of scopes, prominently to the labour market" and that can inform interventions to narrow the gap between higher education and the continent's needs.

Finally, the African Union Commission, in collaboration with the Association of African Universities, developed the African Quality Rating Mechanism (AQRM) as a quality assurance (and assessment) tool in 2007. The AQRM is a product of the harmonisation strategy and aims at improving the "quality of higher education institutions in Africa so as to make them more globally competitive and locally relevant." ${ }^{20}$ The rating mechanism, unlike the ranking schemes, does not list institutions in a league table ${ }^{21}$ but, rather, clusters higher education institutions according to the quality standards ${ }^{22}$ It is, therefore, not implausible to infer that the AQRM provides "an alternative to the existing global ranking/rating systems that do not take into consideration African specificities" ${ }^{23}$ and is skewed towards prestige and status - building. The items in the AQRM align with the contemporary problems that confront African higher education and that were occasioned by the 1980s neglect of higher education in preference for basic education and massification of higher education. These challenges include, inter alia, capacity-building and relevance. ${ }^{24}$

The rating instrument offers higher education institutions an opportunity to conduct self-assessment and compare their performance against similar institutions in 11 areas and on 97 rating items against a common set of criteria. ${ }^{25}$ Nevertheless, the African Union Commission-on a pilot basis(has) dispatches panels of external experts to institutions to validate the selfassessment results and to provide external feedback. The rating criteria have

${ }^{19}$ Hahn and Teferra, "Tuning as instrument," 142-43.

${ }^{20}$ Goolam Muhamedbhai, "Towards an African Higher Education and Research Space (AHEARS): A summary report" (2013) (Association for the Development of Education in Africa).

${ }^{21}$ Oyewole, "The African Quality Rating Mechanism."

22 Shabani, "Quality regimes in Africa."

${ }^{23}$ Okebukola, "Emerging regional developments and forecast."

${ }^{24}$ Oyewole, "The African Quality Rating Mechanisms," 13-14.

25 African Union Commission, African Quality Rating Mechanism (AQRM) survey questionnaire (Addis Ababa: African Union, 2006). 
an institutional-level dimension (governance and management; infrastructure; finance; teaching and learning; research, publication and innovation; and community/societal engagement) and a programme-level dimension (programme planning and management; curriculum development; teaching and learning; assessment; and programme results) ${ }^{26}$ The rating scale comprises five levels: poor (0); insufficient (1); satisfactory (2); good (3); and excellent (4). The AQRM addresses the African Union priorities in the Plan of Action for the Second Decade of Education ${ }^{27}$ and is hypothesised to support the institutional cultures of quality and consequently enhance the quality of African higher education.

Quality and quality assurance are now contemporary buzzwords in the African higher education lexicon and policy discourse. A series of quality assurance initiatives on the continent that are geared towards reversing the apparent deterioration of the quality of higher education are an overt testimony to the quality revolution in Africa. Generally, there is growing international recognition that quality assurance methodologies in any geographical location should align with the dominant notions of quality in higher education. Within Africa, a dearth of empirical studies on the notions or perceptions of quality in higher education at supranational level in general and at the political level, such as the African Union, in particular exists. The extant studies on quality assurance of higher education at the sub-regional and regional level ${ }^{28}, 29$ focus on the quality assurance methodologies rather than the notions of quality, which ought to shape and/or shaped the quality assurance methodologies or both. Therefore, we know little about the notions of quality in higher education at the regional level that the African Union Commission's quality assurance approaches aim at guaranteeing and enhancing, and whether the approaches are compatible with the dominant notions of quality in higher education. The few studies on the notions of quality in higher education are skewed towards the institutional and national levels. Similarly, there is a knowledge gap regarding whether the notions of quality in higher education at institutional level are in sync with the prevailing notions of quality at the African Union level. Finally, there is limited knowledge about the institutional-level quality assurance methodologies that are implicit in the AQRM and which higher education institutions could employ to enhance quality. The notions of quality in higher education and the

\footnotetext{
${ }^{26}$ Oyewole, "The African Quality Rating Mechanisms," 13-14.

${ }^{27}$ Okebukola, "Emerging regional developments and forecast."

${ }^{28}$ Shabani, "Quality regimes in Africa."

29 Shabani, "Quality assurance in Africa."
} 
institutional-level quality assurance practices are latent issues in the quality standards in the AQRM survey questionnaire. Arguably, knowledge of the notions of quality at the continental level can inform a theoretical model for designing quality assurance methodologies which have a regional (or political) outlook but are sensitive to the underlying viewpoints of quality in higher education at both national and institutional levels.

It was against the above backdrop that the AQRM survey questionnaire was examined to answer the following question: What notions of quality in higher education and the institutional-level quality assurance practices are inherent in the quality standards of the AQRM survey questionnaire? The article comprises five sections. The second section follows this introductory section and sketches the methods of the study. The subsequent section presents the findings on the notions of quality in higher education and the institutional-level quality assurance practices that are implicit in the AQRM. Section four discusses the findings while the final section distils conclusions and makes recommendations in light of the findings and the discussions.

\section{Methods}

The article is anchored in interpretivism and the revised AQRM survey questionnaire (January 2014) was the sole source of data. We explored the latent notions of quality in higher education and the institutional-level quality assurance mechanisms (or practices) that are inherent in the questionnaire. The questionnaire was deemed relevant because it comprises quality standards on most facets of quality in higher education from which notions of quality were extrapolated.

Harvey and Green's conceptual model for defining quality in higher education as exceptional, transformation, value for money, consistency (or perfection/zero error) and fitness for purpose ${ }^{30}$ served as the analytical framework for the notions of quality. This stance does not negate the fact that other notions of quality in higher education exist. For example, Astin offers the following five main conceptions of quality for the "modern university": the mystical, reputational, resources, outcomes and value-added views. ${ }^{31}$ However, while Astin's and Harvey and Green's conceptions of quality

${ }^{30}$ Lee Harvey and Diana Green, "Defining quality," Assessment and Evaluation in Higher Education 18, no. 9 (1993): 9-34.

31 Alexander Astin W, "When does a college deserve to be called "high quality?" Current Issues in Higher Education, 2, no 1. (1980):1-9. 
differ in terms of the notions, there is evidently a marked convergence in the substance of the conceptions. We preferred Harvey and Green's model as an interpretive lens because Astin's conceptual model was developed prior to the emergence of the intrinsic dimension of quality in higher education and appears unresponsive to a plethora of the post-1980s changes in the higher education landscape. This partly explicates the occasional use of the model in studies on quality assurance in higher education. We inductively derived the implicit institutional quality assurance practices from the questionnaire.

Content analysis-"a research technique for making replicable and valid inferences from text (or other meaningful matter) to the contexts of their use" ${ }^{\prime 2}$ was employed to make sense of the data. Qualitative content analysis examines the language in a text for the purpose of classifying large amounts of text into categories that represent similar meaning. ${ }^{33}$ Open coding was used, where notes and headings were written in the AQRM questionnaire while being read. Categories and themes were derived from the notes in the questionnaire.

\section{Results}

This section presents the results on the notions of quality in higher education and the institutional-level quality assurance practices that were discerned from the AQRM survey questionnaire (2014).

\section{III.1. Notions of Quality in Higher Education}

As observed in the previous section, Harvey and Green's conceptual model for defining quality in higher education was used to identify the notions of quality in higher education from the AQRM survey questionnaire.

Fitness for purpose

Fitness for purpose as a notion of quality in higher education oscillates between two variants. The first variant is inward-looking (or mission-based)

${ }^{32}$ Klaus Krippendorff K., Content analysis: An introduction to its methodology ( $2^{\text {nd }} \mathrm{ed}$.) (Thousand Oaks: Sage, 2004), 18-19.

${ }^{33}$ Hsiu-Fang Hsieh and Sarah E. Shannon, "Three approaches to qualitative content analysis," Qualitative Health Research 15, no. 9 (2005): 1277-1288. 
and hinges on either the extent to which a higher education institution achieves its mission or a study programme realises its objectives. The focus of this notion is, therefore, the mission of a higher education institution, which may be diametrical to the purpose of higher education in a particular geographical space. Conversely, the final variant pertains to the nexus between a higher education institution's triple missions and the labour market or industry. Therefore, higher education is seen as having a utilitarian or functional role. Under this variant, quality is implied if higher education meets the contemporary and future needs of the customers, notably the employers and governments. However, it ought to be noted that the mission - the raison d'être of a higher education institution - may, in some instances, be externally leaning and thus blur the dividing line between the missionbased and externally-referenced fitness for purpose. The congruence between the mission of the institutions and the needs of the labour market brings another dimension to the quality discourse that is referred to as 'fitness of purpose'. Both variants of fitness for purpose are apparent in the AQRM survey questionnaire, though in varying degrees.

The mission-driven fitness for purpose, though present, is thin in the AQRM survey questionnaire. A single statement which points to fitness for purpose could be isolated from the survey questionnaire. Statement 7.1 under Section 3.1 (programme planning and management) requires institutions to rate themselves on the extent to which "the programme is aligned with the overall mission and vision". ${ }^{34}$ The alignment may indirectly contribute to the realisation of the mission and, therefore, alludes to the fitness for purpose of the programme.

In relation to the externally referenced fitness for purpose, the AQRM survey questionnaire has a series of sections and data collection questions/ statements that lean towards fitness for purpose. First, section 1.8 of the questionnaire is titled "Linkage with the industry sector" and the questionnaire interrogates the nexus (or lack of it) between the higher education institutions and the industrial sector. The question is: "How would you rate the sufficiency of the following linkages with the industry sector in your institution: (a) Responsiveness of curricula to industry and employer participation in curriculum design? (b) Tracer studies/survey of graduates and their employers? (c) Collaborative research undertakings to solve industry problems?"

The question suggests, inter alia, that there should be a tight coupling between the curricula and the research outputs of higher education institutions

${ }^{34}$ African Union Commission, “African Quality Rating Mechanism,” 22. 
and the labour market. The curriculum that is in sync with industry or the labour market requires that the voice of the employers-the consumers of the graduates-should be heard during the curriculum design process. Tracer studies which are part of the question can deepen the nexus between the academy and the labour market. It is likely that the imperative to narrow the gap between the academy and the labour market could have been occasioned by the need to respond to the endemic employers' concerns that the graduates of higher education institutions lack labour market readiness. Finally, the research function of a higher education institution ought to contribute to the resolution of problems of the industrial sector through collaborative research. This demonstrates a shift in the thinking that higher education institutions should not just generate knowledge for the sake of it. Rather, the research outputs should also be initiated by and be beneficial to the external environment of the academy.

The survey questionnaire comprises two sections which underscore the role of higher education institutions, through the research mission, in contributing to national and regional (or Africa's) development. Section 1.9, on pages 12 to 14 , is under the theme "research and community outreach" and the attendant question elicits information on the "proportion of research activities that are relevant to national development". "The section unravels 'relevance' by affirming: "Research that would be undertaken merely for publication purposes in a reputable journal and with little regard to development needs is considered to be not relevant". The AQRM questionnaire visualises a higher education institution through the lens of both a national and a regional organisation. At the regional level, the higher education institution should be concerned with Africa's development. Consequently, section 2.5 (research, publication and innovation) probes whether the research policy of the institution "includes a focus on research supporting African socio-economic development, among others". ${ }^{36}$ Similarly, the section elicits information on whether "researchers are encouraged and facilitated, using research and development budget, ...to engage in research relevant to the resolution of African problems and the creation of economic and development opportunities". ${ }^{37}$ The sections envisage higher education institutions with a pan-African outlook and whose research impact transcends national boundaries. Finally, under section 2.6 (community/societal engagement), the questionnaire interrogates whether " $[\mathrm{t}] \mathrm{he}$ institution offers

35 African Union Commission, "African Quality Rating Mechanism," 12.
36 African Union Commission, "African Quality Rating Mechanism," 19.
37 African Union Commission, "African Quality Rating Mechanism," 20. 
relevant short courses to the community/broader society based on identified needs and identified economic opportunities" 38 and, therefore, attempts to promote a bond between the academy and the broader society.

A central thread in the foregoing discourse is that higher education institutions should skew their triple missions towards social and economic ends. This imperative seems to be intended to curtail the existence or emergence of an elitist attitude in higher education institutions.

Fitness for purpose advocates taking institutional diversity into account while assessing quality to avoid the 'golden standard' trap which occasions an assessment of institutions with differing missions and of different types against a single standard. The AQRM questionnaire takes cognisance of this and uses the results of the assessment to cluster higher education institutions within the context of specific institutional missions. In other words, the ratings are only to be effected on institutions belonging to the same category. Therefore, research-intensive institutions may not feature in the same category as teaching-intensive institutions and vice versa. For researchintensive higher education institutions, the research criteria are weighed more highly than the teaching criteria. Conversely, for teaching-intensive higher education institutions, the teaching criteria receive a higher weight than the research criteria.

Fitness for purpose, especially in the African context, may relate to the fitness of the curriculum of higher education institutions for the African (Union) context. Question 36 on page 11 of the AQRM questionnaire interrogates what is covered under curriculum as trans-disciplinary courses or cross-cutting areas. Of the eleven areas or options, three (African History, African Integration and Pan-Africanism) relate to the African (Union) context. The aim of the course units could be to raise African consciousness and to decolonise (or Africanise) the trans-disciplinary curriculum. Specifically, African History and Pan-Africanism course units resonate with a generic competence of African higher education which was identified by the Tuning Africa Project (commitment to preserve African identify and cultural heritage). On the other hand, two curriculum units hinge on development (sustainable development and national development). This reinforces the notion that the teaching mission of the higher education institution, just like research, should be sensitive to development issues. Furthermore, tolerance features in the survey questionnaire as a transdisciplinary course. Tolerance is particularly important in the African context. Intolerance partly explains the endemic civil wars which undoubtedly

38 African Union Commission, “African Quality Rating Mechanism,” 21. 
retard development in African states. Finally, the extent to which the curriculum reflects "positive African values..." 39 is among the quality standards under the broad assessment theme of curriculum development and stems from the perception that African values have been sacrificed by the education system. This, in part, accounts for the candidature of "professionalism, ethical values and commitment to Ubuntu" (respect for the well-being and dignity of fellow human beings) among the 18 generic competencies of African higher education.

\section{Exceptional}

The exceptional perspective of quality has three variants: exclusivity, meeting minimum standards and exceeding the standards (or excellence). Exclusivity connotes an exclusive, elitist or high-class education institution. The notion of exclusivity which is elitist in nature is untraceable in the survey questionnaire. The absence of the notion can be attributed to the post-1980 shift from elite to mass education and the current recognition that higher education is a right as opposed to a privilege. On the other hand, the notion of quality as meeting the minimum standards is present in the quality standards of the survey questionnaire. It can be argued that an institution has met the quality standards if it is rated good (3) and has excellent quality if it is rated excellent (4). According to the AQRM survey questionnaire, a rating score of 2.8 and 3.5 implies good quality while a rating score greater than 3.5 connotes excellent quality. Within the AQRM, institutions and/or programmes that register excellent scores for at least four consecutive years may become candidates for consideration as African Union Centres of Excellence. Therefore, two out of the three variants of quality as exceptional are implicit in the AQRM survey questionnaire. The AQRM hypothesises that excellence in institutional- and programme-level dimensions would translate into graduates and research outputs that are fit for purpose. The institutional-level dimensions resonate with the endemic challenges of higher education in Africa, among which are poor governance and management, inadequate infrastructure, inadequate funding, and weak linkages between the academy and industry. Furthermore, the institutionallevel dimensions are associated with the capacity challenges of African higher education and explicate the inclination of the AQRM towards, inter alia, capacity-building as opposed to prestige, which is associated with

39 African Union Commission, “African Quality Rating Mechanism,” 24. 
ranking schemes. It can, therefore, be inferred that the challenges in a particular higher education space inform the conceptions of quality and the attendant quality assurance practices.

It should be noted that the AQRM survey questionnaire lacks the benchmarks against which to rate the institutions on the extent to which they fall below the minimum (threshold) quality standards, meet the minimum standards or exceed the threshold standards. This leaves the assessors with the discretion to choose a rating option based on their subjective impressions. This design omission in the AQRM survey questionnaire requires attention so as to bring objectivity into the assessments.

\section{III.2. Quality Assurance Practices at Institutional Level}

Six institutional-level quality assurance practices were discerned from the AQRM survey questionnaire: teaching excellence (or distinguished teacher) awards; staff professional development; rewarding applied research; tracer studies; external examination; and the involvement of external stakeholders in curriculum development.

Distinguished (or excellent) teacher awards

The AQRM survey questionnaire has a quality standard that points to distinguished (or excellent) teacher awards as an internal quality assurance methodology. Specifically, statement 4.1 under the broad thematic area of teaching and learning assesses the extent to which " $[\mathrm{t}]$ he institution encourages and rewards teaching and learning innovation". ${ }^{40}$ Rewarding teaching excellence is an attempt to encourage good teaching practices and to improve the quality of teaching and learning.

Staff professional development

Staff professional development features in the AQRM survey questionnaire. The first area of staff professional development pertains to the teaching (and learning) mission of a higher education institution. Statement 4.2 probes whether " $[\mathrm{t}]$ he institution has procedures in place to

${ }^{40}$ African Union Commission, “African Quality Rating Mechanism,” 18. 
support the induction to teaching, pedagogy, counselling and the upgrading of staff teaching and learning skills through continuing education and lifelong learning". ${ }^{41}$ The capacity development initiatives in the excerpt suggest that staff development is necessary for the delivery of high-quality teaching and learning. As far as the research mission is concerned, statement 5.4 probes whether "the institution has procedures in place to support academic staff to develop and enhance their research skills, including collaborative research and publication" 42 and therefore alludes to staff development.

Rewarding research

Rewarding applied research whose outputs are used by society to solve problems is an implicit institutional-level quality assurance practice in the AQRM survey questionnaire. Statement 5.8 of the AQRM survey questionnaire states that "the institution...rewards research whose results are used by society".$^{43}$ This seems to be a deliberate attempt to re-direct research to serving social and economic ends and is at odds with the basic research paradigm.

\section{Tracer studies}

Tracer studies are identifiable in the AQRM survey questionnaire. Question 37 of the AQRM questionnaire requires the institutional-level respondents to rate the sufficiency of tracer studies/survey of graduates with the industry sector. Generally, tracer studies are intended to elicit information on how the graduates of higher education institutions are doing in the workplace, identify flaws in the academic programmes, and establish whether the academic programmes meet and/or satisfy the critical needs of the employers. They thus serve as a quality assurance methodology and are aligned to the fitness for purpose perspective of quality.

${ }^{41}$ African Union Commission, “African Quality Rating Mechanism,” 18.

${ }^{42}$ African Union Commission, "African Quality Rating Mechanism," 19.

${ }^{43}$ African Union Commission, "African Quality Rating Mechanism," 20. 


\section{External examination}

External examination as a quality assurance practice in higher education is apparent in the AQRM survey questionnaire. The practice is explicit under the teaching and learning dimension of the questionnaire that pertains to assessment. Specifically, statement 10.1 provides for an assessment as to whether "[t]he institution has systems in place for external examination" ${ }^{44}$ External examination is intended to provide an external glimpse into students' assessment and to gauge whether the marking of scripts is objective and the assessment items measure up to the level being assessed.

\section{Involvement of key external stakeholders in curriculum development}

The drive towards narrowing the gap between the training programmes of higher education institutions and the needs of the labour market necessitates the involvement of employers in the curriculum development and review processes. The gap between the curriculum and the needs of the labour market partly explicates the lack of work readiness of the graduates. Under the programme planning and management component of the AQRM survey questionnaire, statement 8.6- "Curriculum development has been informed by thorough research and consultation with relevant stakeholders including public sector planners, industry and other employers" 45 - relates to the involvement of external stakeholders in the curriculum development process. The purpose is to ensure that the curriculum is relevant to the world of work. A curriculum which is relevant to the labour market, if supplemented by effective and adequate resources, is likely to produce graduates who are responsive to the demands of the labour market.

\section{Discussion}

The AQRM survey questionnaire is aligned to the traditional (exceptional) and contemporary (fitness for purpose) notions of quality. Whereas all the variants of fitness for purpose could be isolated from the AQRM, two out of the three variants of quality as exceptional - namely meeting minimum standards and excellence - were implicit in the rating mechanism. The

\footnotetext{
44 African Union Commission, “African Quality Rating Mechanism,” 25.

45 African Union Commission, "African Quality Rating Mechanism," 24.
} 
findings on the perspectives of quality that are implicit in the AQRM lend credence to Oyewole ${ }^{46}$ who asserted that fitness for purpose and excellence are among the hallmarks of the AQRM. Nevertheless, fitness for purpose is the dominant notion of quality in higher education. The results are in sync with the extant studies on the perceptions of quality assurance at institution level which revealed that academics perceive quality as fitness for purpose and exceptional ${ }^{47}$ The convergence in the notions of quality at the African Union and institutional levels has the potential to enhance the adoption of the AQRM by higher education institutions. The chances of the adoption of a quality assurance methodology are fewer if it is not aligned to the notions of quality in higher education in a particular higher education space.

The exclusivity variant of exceptional was latent in the tool. The drive to increase the participation rates in higher education and the shift from elite to mass higher education, coupled with the norm-referenced nature of exclusivity, could account for the lack of traces of it in the AQRM. The AQRM survey questionnaire is criterion-referenced (or standards-based) and is unlikely to accommodate an overly norm-referenced notion of quality which assumes that inaccessibility of the elite education implies quality.

The survey questionnaire does not provide explicit benchmarks to inform self-rating by institutions and validation of the results by the African Union Commission. In some instances, it comprises generic and subjective words such as 'sufficient', 'appropriate' and 'in line with acceptable norms'. The five levels of assessment (poor, insufficient, satisfactory, good and excellent) do not provide standards-based descriptors. If excellence connotes exceeding minimum quality standards, then it is logical that the level descriptors are provided to guide the rating and to enable a distinction to be made between threshold standards, excellence (exceeding the minimum/ threshold standards) and below the standard(s). For example on infrastructure, rather than a generic statement such as "The institution has sufficient lecturing spaces to accommodate student numbers taking the institutional mode of delivery into account", the level descriptors could have square metres per student for each assessment level and for the various modes of delivery.

The dominance of fitness for purpose could be based on the notion that "the definition of quality as fitness for purpose has shown to be potent in developing an educational policy and educational practices to help the

\footnotetext{
46 Oyewole, "The African Quality Rating Mechanisms," 12.

47 Nabaho, "Making sense of an elusive concept," 38.
} 
countries climb out of their chronic and potentially crippling predicaments." ${ }^{48}$ Africa's predicaments are explicit in the vision of the African Union and Agenda 2063. The foregoing discourse demonstrates that the political agenda at the African Union level informs the conception of quality in higher education. Therefore, quality can be a political creature. It could also be a strategy to re-direct higher education to serve economic and social ends, which it may be deemed to pay less to attention or to neglect.

The transformative or value-added notion of quality in higher education is non-existent in the AQRM. This can be explained by the difficulties in measuring and applying the transformative view of quality, that is, the difference between the input (student knowledge and competence before higher education) and output (student knowledge and competence after higher education). ${ }^{49}$ Assessing transformation requires baseline data upon which the degree of value added (transformation) after the students' higher education experience can be gauged. We need to add a caveat: absence of transformation does not imply that the transformative perspective of quality is excluded on the list of the African Union Commission's definitions of quality in higher education. Transformation presupposes the "fundamental purpose of higher education" ${ }^{50}$ and Westerheijden, Stensaker and Rosa ${ }^{51}$ aptly argue that "[t]he aim of higher education, and especially of students' first experience of higher education, is to assist students to be transformed from adolescents with school-type knowledge into adults ready to enter society and the labour market at the highest level of competencies available."

Six quality assurance practices were discerned from the AQRM survey questionnaire: distinguished (excellent) teacher awards, staff professional development, rewarding research, tracer studies, external examination and the involvement of external stakeholders in curriculum development. The practices have the potential to enhance quality owing to the degree of alignment between them and the notions of quality that are implicit in the AQRM survey questionnaire. The practices resonate with the findings from

${ }^{48}$ Nirwan Idrus, "Transforming quality for development," Quality in Higher Education 9 , no.2 (2003): 141-150.

49 Jens Jungblut, Martina Vukasovic, and Bjorn Stensaker, "Student perspectives on quality in higher education," European Journal of Higher Education 5, no. 2 (2015), https://doi. org/10.1080/21568235.2014.998693.

${ }^{50}$ Lee Harvey and Peter Knight, Transforming higher education (Buckingham, UK: SRHE and Open University Press, 1996), 14.

${ }^{51}$ Don F. Westerheijden, Bjorn Stensaker, and Maria Joao Rosa, Introduction to quality assurance in higher education. Trends in regulation, translation and transformation, ed. Don F. Westerheijden, Bjorn Stensaker, and Maria Joao Rosa (Dordrecht: Springer, 2007), 7. 
the studies at institutional level..$^{52}$ Therefore, the latent quality assurance practices in the AQRM questionnaire do not operate at cross purposes to those at institutional level. The rewards component of the methodologies (rewarding teaching and distinguished teacher awards) is intended to enhance the quality of teaching and research and is informed by the notion that behaviour that receives positive consequences tends to be repeated. The AQRM occasions a paradigm from rewarding any type to rewarding research whose outputs are used by society. This quality assurance mechanism is intended to narrow the gap between the research function and the needs of society. Teaching excellence awards are intended to enable the recognition and celebration of excellent teachers as well as the promotion of teaching excellence; to enable dissemination of excellent teaching practice; ${ }^{53}$ and to symbolically acknowledge support for teaching, to honour excellent teachers, or to create teaching role models who can motivate other faculty to enhance their own practice. ${ }^{54}$ Teaching excellence awards, if they are to work effectively, require that the dimensions of teaching excellence are identified. These may vary from jurisdiction to jurisdiction. However, Gunn and Fisk ${ }^{55}$ have identified the following generic dimensions of teaching excellence: planning and delivery; assessment; contribution to the profession; and reflection and evaluation. Rewarding teaching excellence could be intended to create parity of esteem of research and teaching. Traditionally, owing to the 'publish or perish' dictum, research is held in high esteem compared to teaching. The celebrity status accorded to research militates against improvement of teaching, which some academics may consider a kiss of death.

The range of quality assurance approaches at institutional level is quite limited in the AQRM as can be evident from the six quality assurance practices that were distilled from it. Quality is a multi-dimensional concept whose assurance should be democratised to employ a range of quality assurance practices. Quality assurance practices, such as student evaluation of teaching, which provide feedback to the teachers for reflection and

${ }^{52}$ Ephraim Mhlanga, "Quality assurance in higher education in Southern Africa: The case of the universities of Witwatersrand, Zimbabwe and Botswana" (PhD thesis, University of Witwatersrand, 2008).

${ }^{53}$ Vicky Gunn and Anna Fisk, Considering teaching excellence in higher education: 2007-2013: A literature review since the CHERI report 2007 (Higher Education Academy, 2013).

${ }^{54}$ Nancy Van Note Chism, "Teaching awards: What do they award?" The Journal of Higher Education 77, no. 4 (2006): 589-617.

${ }_{55}$ Gunn and Fisk, "Considering teaching excellence in higher education." 
improvement in teaching, are not traceable in the AQRM. Student evaluation teaching results serve as evidence for distinguished teacher awards. Other quality assurance approaches which are missing in the AQRM questionnaire include, among others, peer-observation of teaching and moderation of examination items.

It is now time to reflect upon the AQRM and assess the 'African' in it beyond the name. The AQRM epitomises a search for an African quality assurance approach to deal with the $21^{\text {st }}$ century challenges of African higher education. Unlike the other quality assurance approaches that have been influenced by mimetic isomorphism (or policy imitation), the AQRM connotes an invention in the domain of quality assurance. It takes cognisance of the autonomy of higher education institutions to design and implement academic programmes but within the regional quality standards. However, it should be noted that all the institutional-level quality assurance practices mirror those in higher education systems of advanced economies and this attests to the internationalisation of quality assurance. ${ }^{56}$

The article contributes to the limited literature on quality assurance at the regional level. It provides insights into the African Union Commission's perspective of quality and quality assurance and-from the African Union Commission's perspective-the institutional-level quality assurance practices which higher education institutions in Africa should either adopt or strengthen to meet the quality standards in the AQRM.

\section{Conclusions and recommendations}

From the findings and the discussion, it can be inferred that quality assurance approaches in a particular jurisdiction do not take place in a vacuum. The contemporary problems pertaining to higher education in a particular geographical space occasion the notions of quality and the resultant architecture of quality assurance. The perceived decoupling of the missions of the university from society and the low human, financial and physical capacity of the institutions influenced the texture of the AQRM. Therefore, the prevailing context of higher education shapes the quality assurance practices. This suggests that the designers of quality assurance models for highereducation, regardless of the context and level of economic development,

${ }^{56}$ Lazarus Nabaho, Jessica Aguti, and Joseph Oonyu, "Assuring the quality of teaching at Makerere University in Uganda: Practices and experiences of academics and students," Alternation 23, no. 1 (2016):55. 
should pay close attention to the contextual specificities. Secondly, the existing notions of quality shape the quality assurance practices. The tight coupling between the perception of quality and the methodology of the AQRM lends credence to this assertion.

The findings have further revealed design gaps in the AQRM survey questionnaire and specifically those that relate to the absence of benchmarks to guide assessments and the limited number of quality assurance practices for consideration by institutions. Against the background of the foregoing narrative, it is recommended that the African Union Commission should develop benchmarks and level descriptors for the quality indicators in the questionnaire to guide assessment and to guarantee objectivity of the assessments. Finally, the statements that are suggestive of the institutionallevel quality assurance practices should be broadened to include practices such as student evaluation of teaching and peer observation of teaching.

\section{Bibliography}

African Union Commission. Second Decade of Education for Africa (2006-2015) Plan. Addis Ababa: African Union Commission, 2006.

- Agenda 2063: The Africa We Want. Addis Ababa: African Union Commission, September 2015.

- African Quality Rating Mechanism (AQRM) survey questionnaire. Addis Ababa: African Union, 2014.

- Continental Education Strategy for Africa 2016-2025. Addis Ababa: African Union Commission, 2016.

Astin, Alexander W. "When does a college deserve to be called "high quality'?" Current Issues in Higher Education 2, no.1 (1980), 1-9.

Bloom, David, Canning David, Chan Kevin, and Luca Dara Lee. "Higher education and economic growth in Africa." International Journal of African Higher Education 1, no.1 (2014): 23-57. https://doi.org/10.6017/ijahe.v1i1.5643.

Chism, Nancy Van Note. "Teaching awards: What do they award?" The Journal of Higher Education 77, no. 4 (2006): 589-617.

Gunn, Vicky, and Fisk Anna. "Considering teaching excellence in higher education: 2007-2013: A literature review since the CHERI report 2007.” Higher Education Academy (2013).

Hahn, Karola, and Damtew Teferra. "Tuning as instrument of systematic higher education reform and quality enhancement: The African experience." Tuning Journal for Higher Education 1, no. 1 (2013): 127-63.http://dx.doi.org/10.18543/ tjhe-1(1)-2013pp127-163.

Harvey, Lee, and Green Diana. "Defining quality." Assessment and Evaluation in Higher Education 18, no.1 (1993): 9-34. 
Harvey, Lee, and Peter Knight. Transforming higher education. Buckingham, UK: SRHE and Open University Press, 1996.

Hsieh, Hsiu-Fang, and Shannon Sarah. "Three approaches to qualitative content analysis." Qualitative Health Research 15, no. 9 (2015): 1277-1288. https://doi. org/10.1177/1049732305276687.

Idrus, Nirwan, “Transforming quality for development." Quality in Higher Education 9, no. 2 (2003): 141-150.

"Information Technology should be used to tap knowledge from greatest Universities to bring learning to all, Kofi Annan says. "United Nations Information Service. Published August 2, 2000. https://www.un.org/press/en/2000/20000802. sgsm7502.doc.html.

Jungblut, Jens, Martina Vukasovic, and Bjorn Stensaker. "Student perspectives on quality in higher education." European Journal of Higher Education (2015). Accessed February 12, 2018. http://dx .do1.org/10.1080/21568235.2014.998693.

Krippendorff, Klaus. Content analysis: An introduction to its methodology ( $2^{\text {nd }}$ ed.). Thousand Oaks: Sage, 2004.

Malcolm, Gillis (1999) cited in World Bank. Higher education in developing countries: Peril and promise. Washington, DC: The World Bank, 2000.

Mhlanga, Ephraim. "Quality assurance in higher education in southern Africa: The case of the universities of Witwatersrand, Zimbabwe and Botswana." $\mathrm{PhD}$ thesis, University of Witwatersrand, 2008.

Muhamedbhai, Goolam. "Towards an African Higher Education and Research Space (AHEARS): A summary report." Association for the Development of Education in Africa, 2013.

Nabaho, Lazarus, Jessica Aguti, and Joseph Oonyu. "Assuring the quality of teaching at Makerere University in Uganda: Practices and experiences of academics and students." Alternation 23, no.1 (2016): 40-61.

_. "Making sense of an elusive concept: Academics' perspectives of quality in higher education." Higher Learning Research Communications 7, no. 2 (2017). https://doi.org/10.18870/hlrc.v7i2.383.

Nabaho, Lazarus. "Developing generic competences in life sciences: The untold story of the Makerere University College of Health Sciences in Uganda." Tuning Journal for Higher Education 4, no. 2 (2017). http://dx.doi.org/10.18543/tjhe4(2)-2017pp389-406.

Oyewole, Olusola. "The African quality rating mechanisms: The process, prospects and risks." Paper presented at the Fourth International Conference on Quality Assurance in Higher Education in Africa and Capacity Building (Training) Workshop, Bamako, October 5-10, 2010. http://ifgu.auf.org/media/document/ KEYNOTE_Oye_AQRM_ProcessProspect_and_Risks_2.pdf.

Shabani, Juma. "Quality regimes in Africa: The reality and the aspirations." Chronicles of Higher Education 4 (May 2013):1-3.http://www.inhea.org/ wpcontent/uploads/2016/02/Quality-Regimes-in-Africa-For-posting.pdf.

Shabani, Juma, Peter Okebukola, and Oyewole Olusola. "Quality assurance in Africa: Towards a continental higher education and research space." International 
Journal of African Higher Education 1, no.1 (2014): 139-171. https://doi. org/10.6017/ijahe.v1i1.5646

Okebukola, Peter A. "Emerging regional developments and forecast for quality in Higher education in Africa" (Paper presented at the 2014 CHEA International Quality GROUP Annual Conference, Washington DC, USA, January 29-30. http://citeseerx.ist.psu.edu/viewdoc/download?doi=10.1.1.638.4444\&rep=rep1 \&type $=$ pdf

Westerheijden, Don F., Bjorn Stensaker, and Maria Joao Rosa. Introduction to quality assurance in higher education. Trends in regulation, translation and transformation, edited by Don F. Westerheijden, Bjorn Stensaker, and Maria Joao Rosa, 1-11. Dordrecht: Springer, 2007.

Woldegiyorgis, Emnet. "Conceptualizing harmonization of higher education systems: The application of regional integration theories on higher education studies." Higher Education Studies 3, no. 2 (2013). Accessed February 14, 2019. https://doi.org/10.5539/hes.v3n2p12.

World Bank. Constructing knowledge societies: New challenges for tertiary education. Washington, DC: World Bank, 2002.

\section{About the authors}

LAZARUS NABAHO (lnabaho@umi.ac.ug) is a Senior Lecturer at Uganda Management Institute. He holds a PhD in Educational Management of Makerere University, Uganda. His research interests include higher education governance, teaching and learning, student assessment, and quality assurance in higher education.

WILBERFORCE TURYASINGURA (wturyasingura@umi.ac.ug) is the Dean of the School of Business and Management at Uganda Management Institute. He holds a $\mathrm{PhD}$ in Management from Wits University, South Africa. His research interests include knowledge management, performance management, strategic management, and human resource development. 


\section{An exploration of the 'African (Union Commission's) perspective' of quality and quality assurance in higher education: Latent voices in the African Quality Rating Mechanism (AQRM)}

Lazarus Nabaho and Wilberforce Turyasingura

doi: http://dx.doi.org/10.18543/tjhe-6(2)-2019pp73-95

\section{Copyright}

Copyright for this article is retained by the Publisher. It is an Open Access material that is free for full online access, download, storage, distribution, and or reuse in any medium only for noncommercial purposes and in compliance with any applicable copyright legislation, without prior permission from the Publisher or the author(s). In any case, proper acknowledgement of the original publication source must be made and any changes to the original work must be indicated clearly and in a manner that does not suggest the author's and or Publisher's endorsement whatsoever. Any other use of its content in any medium or format, now known or developed in the future, requires prior written permission of the copyright holder. 